\title{
Cultura virtual e subjetividade na idade mídia: contemplações críticas com Joana Peixoto'
}

\author{
Evandro Saluador Alves Oliveira ${ }^{2}$ \\ Centro Universitário de Mineiros, Professor Adjunto \\ Henrique Carivaldo de Miranda $\mathrm{Neto}^{3}$ \\ Centro Universitário de Patos de Minas, Docente \\ Júlio Henrique Cunha Neto 4 \\ Universidade de Uberaba (UNIUBE), Doutorando
}

\begin{abstract}
Sálua Cecílio
Universidade de Uberaba (UNIUBE), Coordenadora do Programa de Pós-G,raduação em Educação
\end{abstract}

Resumo: A temática da cultura virtual e midiática presente nas discussões instauradas na academia traz pontos e contrapontos que oportunizam críticas e debates. Por um lado, desafiam consensos capazes de cristalizar e engessar ideias e ações, por outro, distorcem imagens tão bem desenhadas na história das telecomunicações. Nessa direção, o propósito dessa entrevista é trazer à tona algumas contemplações sobre as controvertidas relações entre educação e tecnologias na sociedade neoliberal e seus efeitos na produção de subjetividades. Para tanto, debruçamo-nos sobre esse campo de conhecimento, por meio de uma entrevista realizada com a pesquisadora brasileira, Joana Peixoto (J.P.), que se destaca no cenário nacional pelos legados e inúmeras contribuições registradas na área em que atua. Considerando a larga experiência como pesquisadora e docente na área da educação, apresentamos, de modo breve, um panorama da formação da entrevistada, bem como os interesses que possui. Joana Peixoto possui produção arbitrada e divulgada em periódicos qualificados com trabalhos científicos. Por essa razão pensamos ser muito relevantes as experiências constituídas pela Professora no terreno da formação de professores, assim como as relações com as mídias eletrônicas e tecnologias digitais.

Palavras-chave: Cultura virtual. Mídias e tecnologias. Subjetividades.

Recebida em 7 de dezembro de 2018

Aceita em 19 de março de 2019

Publicada em 19 de março de 2019

Esta entrevista é fruto de um trabalho desenvolvido no componente curricular Cultura Virtual e Subjetividade, do Programa de Pós-Graduação em Educação (doutorado) da Universidade de Uberaba (UNIUBE), e integra atividades de pesquisa de um projeto financiado pelo CNPq (processo 4567902014-4).

2 Doutorando em Estudos da Criança pela Universidade do Minho (UMINHO/Portugal); Doutorando em Educação pela Universidade de Uberaba (UNIUBE); Mestre em Educação pela UFMT/Rondonópolis; https://orcid.org/0000-0003-2228-9776; http://lattes. cnpq.br/5274236766335775.

3 Doutorando em Educação pela Universidade de Uberaba (UNIUBE); Mestre em Educação Superior pelo Centro Universitário do Triângulo; https://orcid.org/0000-0003-0629-1534; http://lattes.cnpq.br/2829577110803247.

4 Doutorando em Educação pela Universidade de Uberaba (UNIUBE); Mestre em Educação pela Universidade Federal do Triângulo Mineiro; https://orcid.org/0000-0003-0090-6913; http://lattes.cnpq.br/9759997035527935.

5 Doutora em Sociologia pela Universidade de São Paulo; Mestre em Psicologia Social pela Pontifícia Universidade Católica de São Paulo; https://orcid.org/0000-0001-6035-1636; http://lattes.cnpq.br/4895228131417940. 


\section{SOBRE A ENTREUISTADA ${ }^{6}$}

A professora Joana Peixoto possui graduação em Pedagogia pela Universidade Federal de Goiás (1982), especialização em Informática e Educação pela Unicamp (1989), mestrado em Educação pela Universidade Federal de Goiás (1991), Approches Plurielles en Sciences de Éducation (DEA) (2002) e doutorado em Ciências da Educação pela Universidade Paris 8 (2005). Atualmente é Professora no Mestrado Profissional em Educação para Ciências e Matemática no Instituto Federal de Educação, Ciência e Tecnologia de Goiás e colaboradora no Programa de Pós-Graduação Strictu Sensu em Educação da PUC Goiás. É líder do Kadjót - Grupo de Estudos e Pesquisas sobre as relações entre as tecnologias e a educação. Tem experiência em formação de professores, com ênfase na área de tecnologia e educação, atuando principalmente nos seguintes temas: tecnologia e educação, informática e educação, mídia e educação, educação a distância e na relação desses temas com a formação de professores.

Pesquisadores: Como ocorreu o seu envolvimento com a temática das Mídias na Educação? Há quanto tempo isso ocorreu e por quais razões? Comente o seu processo formativo ressaltando relações entre sua graduação e pós-graduação com a atuação docente e as pesquisas que vem realizando.

J. P.: Meu primeiro contato com o computador ocorreu em 1988 quando cursei uma especialização em Informática e Educação na Unicamp (fazia parte do Formar ll, ação do Ministério da Educação, ligado ao Projeto Educom). Na época eu trabalhava na Escola Técnica Federal de Goiás, e o Governo Federal ofereceu esse curso para servidores de escolas técnicas e instituições de ensino superior, com vistas à formação de recursos humanos para a implantação de Centros de Informática Aplicada à Educação em suas instituições de origem. Embora trabalhasse numa instituição de educação tecnológica, nunca havia tocado num computador. Este recurso ainda era destinado apenas aos pesquisadores no campo da Informática.

0 curso foi muito interessante. 0s professores, oriundos de diversas instituições, apresentavam propostas distintas de aplicação da informática aos processos pedagógicos, embora a concepção predominante fosse baseada em pressupostos piagetianos: utilização da linguagem Logo de Programação para o desenvolvimento do raciocínio lógico e adoção do método clínico piagetiano para a pesquisa na área. José Armando Valente (Unicamp) exerceu a coordenação e tivemos diversos outros professores da Unicamp, e mais Léa da Cruz

As informações prévias sobre a autora foram retiradas do currículo disponivel na Plataforma Lattes. 
Fagundes (UFRGS), Waldemar Setzer (USP), Frederico Litto (USP), assim como docentes da UFMG que se dedicavam à produção de softwares educacionais.

Ao retornar à minha instituição, após a conclusão do curso de Especialização, eu e mais três professores nos dedicamos à criação do Centro de Informática Aplicada à Educação da Escola Técnica (CIET).

Então, esse curso de Especialização se constituiu no marco do meu envolvimento com a temática. 0 que provocou o meu interesse pelo uso das tecnologias na educação foi a preocupação com a qualidade do ensino. Estava preocupada com a qualidade da educação em geral e insatisfeita com aspectos de minha prática como professora, e o recurso às tecnologias me parecia uma maneira de colocar em questão práticas pedagógicas cristalizadas.

Alguns anos depois iniciei trabalho como docente na Universidade Católica de Goiás. Participei do processo de elaboração da ementa da então criada disciplina Informática e Educação, que posteriormente foi reformulada e denominada Educação, Comunicação e Mídia.

Em 2005 conclui Doutorado em Ciências da Educação, cujo tema foi as representações que os formadores de professores constroem sobre o papel do computador na educação. Os sujeitos da pesquisa foram os meus colegas, professores da disciplina Informática e Educação da UCG.

A experiência como docente das disciplinas Informática e Educação e, posteriormente, Educação, Comunicação e Mídia na UCG (PUC Goiás) me envolveu em estudos que embasaram a organização do trabalho pedagógico (planejamento, condução das aulas, avaliação e produção de material didático). Tais estudos envolveram distintas áreas do conhecimento em diferentes abordagens: antropologia, políticas educacionais, psicologia educacional, tanto em abordagens ditas críticas quanto as pós-modernas.

0 tratamento do tema carecia, para mim, de uma consistência teórico-metodológica e de princípios que pudessem orientar o trabalho pedagógico. Como o trabalho de doutorado comprovou: a discussão sobre o uso de tecnologias na educação consegue atingir uma dimensão crítica quando abordada na perspectiva das macropolíticas, mas se mantém em uma dimensão ingênua, quando se dedica aos aspectos didático-pedagógicos. Explicando melhor: quando se trata de pensar a introdução das tecnologias na educação do ponto de vista de um projeto econômico neoliberal, estas aparecem como recursos políticos e econômicos para impor um modelo excludente e fundamentado em uma racionalidade instrumental que separa meios e fins, afirmando a desigualdade social e a diferença de classes. Segundo tal leitura, as tecnologias são instrumentos de dominação e não podem servir a um projeto de educação emancipadora. Para "resolver" esse paradoxo, o tratamento do uso pedagógico dos recursos tecnológicos se distancia de uma leitura política e recorre a distintas (e às vezes antagônicas) teorias pedagógicas para atestar os benefícios do uso das tecnologias na educação. 
Esse paradoxo, que subsiste ao meu trabalho de doutorado, norteará a continuidade de meus estudos no seio do Kadjót (Grupo de Estudos e Pesquisas sobre as relações entre as tecnologias e a educação), criado em 2007, quando passo a integrar o corpo docente do Programa de Pós-graduação em Educação da PUC Goiás.

Na sequência dos estudos e reflexões sobre as relações entre as tecnologias e a educação, alguns eixos de análise foram sendo configurados. Alguns deles serão referidos nas respostas às questões a seguir.

Pesquisadores: Somos atravessados por uma ideologia neoliberal, que demanda um maior grau de eficiência e produtividade de todos os segmentos profissionais e da sociedade como um todo. Nesse sentido, aos professores também são apresentadas exigências na mesma direção. Tem-se, portanto, uma condição de trabalho em que, aos professores, cabe maior envolvimento e dedicação para atingir a eficiência e o grau de produção esperados. Sobre tal contexto de trabalho, na sociedade neoliberal, perguntamos: você concorda que é condição para a sobrevivência produzir cada vez mais? Considera haver um papel das tecnologias em tal processo? Por outro lado, admite ser destinado aos profissionais da educação um papel específico diante das exigências de mercado, em tempos de constantes renovações tecnológicas?

J. P.: As tecnologias são instrumentos privilegiados de expressão do projeto neoliberal em curso. Associadas ao conhecimento científico, as tecnologias fornecem justificativas e argumentos de ordem teórica e prática para justificar a concentração do conhecimento e do poder nas mãos de poucos e impor a racionalidade instrumental como discurso hegemônico. Essa perspectiva considera a luta de classes como elemento explicativo do campo de forças que configura a sociedade. Dessa maneira, podemos pensar em, pelo menos, duas formas para articular as tecnologias aos processos formativos, o que desembocaria em duas perspectivas para o trabalho docente.

Por um lado, o projeto do capital - internacional - que atribui à educação o papel de preparar indivíduos para vender a sua força de trabalho em um mercado concentrador de riquezas. De outro lado, um projeto contra-hegemônico, que intenta se apropriar da contradição inerente a esse projeto, constituindo ferramentas teórico-práticas para o estabelecimento de ações de resistência e de afirmação de um projeto democrático e popular. Ou seja, não existe um papel para o professor na sociedade atual: existem possibilidades distintas, em razão do tipo de projeto formativo (vale dizer de homem e de sociedade) adotado por cada professor, ou melhor, por cada coletivo de professores, porque a ação docente possui uma dimensão social. 
Pesquisadores: Levando em consideração a era da convergência midiática e os tempos da "idade mídia", em que subjetividades de professores correm o risco de serem colocadas em suspenso, a partir de relações ampliadas e plurais com tecnologias digitais, indagamos: na sua visão, quais são os principais efeitos e impactos que "as novas fronteiras da indústria e dos serviços" - consideradas por Raquel Barreto (2012) como "meios econômicos" - causam nos indivíduos em suas interfaces com os dispositivos de mídia eletrônica, como celulares, smartphones, tablets e computadores?

J. P.: 0 processo recente de disseminação das mídias digitais em rede não é uma fatalidade e muito menos um fenômeno de ordem exclusivamente técnica. Podemos considerar com Milton Santos (em seu livro Por uma outra globalização: do pensamento único à consciência universal uma dinâmica de rupturas e continuidades. Ou seja, a "idade mídia" é resultado de um processo historicamente construído. Assim como as mídias, os sujeitos sociais também são condicionados pelo contexto sócio-histórico que os constitui. Então, essa disseminação das mídias encontra sujeitos humanos que são frutos de experiências formativas fragmentadas, teoricamente frágeis, marcadas por um pensamento instrumental e uma moral conservadora e preconceituosa. Com essa observação, quero chamar a atenção para o fato de que o processo de massificação que coloca a subjetividade em risco não é efeito (apenas) da tecnologia ou da presença marcante dos aparatos tecnológicos. Os meios tecnológicos digitais em rede são elementos que compõem o projeto civilizatório em curso, que é centrado na economia. Esse projeto articula a tecnologia, o conhecimento científico, o conhecimento filosófico e a arte em tramas que obscurecem o pensamento autônomo.

Pesquisadores: Considerando o enfraquecimento e/ou a diluição de fronteiras entre trabalho docente e vida pessoal, em razão da onipresença de tecnologias que impulsionam o ritmo de trabalho na sociedade do século XXI, a que caminhos esse fenômeno pode nos levar? Quais as possiveis implicações no campo educacional? Quais as decorrências do uso de tecnologias para o trabalho docente, em especial no ensino superior?

J. P.: Considero importante retomar a base marxista do pensamento frankfurtiano para resgatar alternativas emancipadoras para a educação e para $\circ$ trabalho docente. A indústria cultural quer reduzir ao máximo o pensamento, afirmando a massificação do trabalho, da arte, da cultura, da ciência. Então, apenas a contradição - como categoria do método dialético - pode apontar alternativas para a dominação total, o fim definitivo do sujeito humano e a eliminação da possibilidade de formação.

0 sujeito tem reduzida autonomia, mas não é totalmente submisso diante da tecnologia e do que ela representa. Existe uma margem, mesmo que restrita para o pensamento, que pode se libertar da dominação da lógica técnico-científica. É nessa margem 
que reside a possibilidade de resistência. Por isso, estou de acordo com Nelson Pretto (pesquisador da UFBA) quando diz que o uso da tecnologia não facilita o trabalho pedagógico. A integração das tecnologias a processos educacionais críticos não é uma tendência inevitável da cibercultura (como afirma Pierre Lévy). Pelo contrário, a tendência que predomina é de uma educação instrumental, que faz uso igualmente instrumental das mídias digitais em rede. A apropriação crítica das tecnologias se insere num movimento de resistência, numa ação contra-hegemônica que contesta a educação orientada por princípios econômicos neoliberais. Por isso, não é tarefa fácil e não vai contar com a adesão do projeto ideológico hegemônico.

Pesquisadores: Este é um espaço para outras considerações e comentários que julgar pertinentes.

J. P.: Agradeço a oportunidade que esta entrevista me provocou de pensar sobre a minha trajetória como pesquisadora e como professora. Espero poder igualmente provocar reflexões nos leitores.

\section{REFERÊNCIAS}

BARRETO, R. G. A recontextualização das tecnologias da informação e da comunicação na formação e no trabalho docente. Educação e Sociedade. Campinas, v. 33, n. 121, p. 985-1002, out./dez. 2012.

Endereços para correspondência: Rua 22, 356, St. Aeroporto, Centro Universitário de Mineiros (UNIFIMES), 75833-130, Mineiros, Goiás, Brasil; evandro@unifimes.edu.br 